\title{
A rat model of FOLFOX-induced neuropathy: effects of oral dimiracetam in comparison with duloxetine and pregabalin
}

\author{
Lorenzo Di Cesare Mannelli ${ }^{1}$ (D) Mario Maresca $^{1}$ Laura Micheli $^{1} \cdot$ Carlo Farina $^{2}$. \\ Michael W. Scherz ${ }^{2}$. Carla Ghelardini ${ }^{1}$
}

Received: 21 July 2017 / Accepted: 6 October 2017 / Published online: 12 October 2017

(c) Springer-Verlag GmbH Germany 2017

\begin{abstract}
Background and aim The FOLFOX family of chemotherapy regimens are hampered by the development of a painful neuropathy. Current clinical treatments are inadequate, and furthermore, the research of innovative drugs is strongly disadvantaged by the absence of a preclinical model based on the complete mixture of FOLFOX components. The aim of this study was to set up a rat model of FOLFOX-induced neuropathy in rats, validate its predictability by reference drugs, and evaluate the effectiveness of the new anti-neuropathic compound dimiracetam.

Methods Male Sprague-Dawley rats were treated intraperitoneally with the FOLFOX components $\left(6 \mathrm{mg} \mathrm{kg}^{-1}\right.$ oxaliplatin, $50 \mathrm{mg} \mathrm{kg}^{-1} 5$-FU, $90 \mathrm{mg} \mathrm{kg}^{-1}$ leucovorin calcium salt) or oxaliplatin alone $\left(6 \mathrm{mg} \mathrm{kg}^{-1}\right)$ on days 0,7 , 14 , and 21 , whereas a separate group received one more injection of FOLFOX on day 28. Pain behavioural measurements (paw pressure, cold plate, and electronic Von Frey tests) and motor coordination (Rota-rod test) were assessed before and after treatments. Behavioural, motor, neurological, and autonomic parameters (open field and Irwin tests) were evaluated.
\end{abstract}

Electronic supplementary material The online version of this article (doi:10.1007/s00280-017-3449-8) contains supplementary material, which is available to authorized users.

Lorenzo Di Cesare Mannelli

lorenzo.mannelli@unifi.it

1 Department of Neuroscience, Psychology, Drug Research and Child Health, Neurofarba-Pharmacology and Toxicology Section, University of Florence, Viale G. Pieraccini, 6, 50139 Firenze, Italy

2 Metys Pharmaceuticals AG, Leimenstrasse 57, 4055 Basel, Switzerland
Results FOLFOX reduced the pain threshold in response to mechanical noxious and thermal (cold) non-noxious stimuli beginning from day 14 up to day 42 comparably to oxaliplatin alone. A fifth FOLFOX injection enhanced the severity but not the duration of painful alterations. Spontaneous activity, behavioural, autonomic, and neurological functions were also affected, whereas the motor coordination was not altered. On day 22 , duloxetine $\left(15 \mathrm{mg} \mathrm{kg}^{-1}\right.$, per os), morphine (10 $\mathrm{mg} \mathrm{kg}^{-1}$, subcutaneously), or pregabalin (20 $\mathrm{mg} \mathrm{kg}^{-1}$, per os), acutely administered, reduced the FOLFOX-dependent hypersensitivity. Repeated treatments with dimiracetam $\left(150 \mathrm{mg} \mathrm{kg}^{-1}\right.$, per os, twice daily, from day 22) significantly protected rats from FOLFOX-induced alterations of pain threshold as well as from autonomic and neurological impairments taking effect after 7 days treatment. Pregabalin repeatedly administered $\left(20 \mathrm{mg} \mathrm{kg}^{-1}\right.$, per os, twice daily, from day 22) was less effective in reducing mechanical hypersensitivity.

Conclusion A clinically consistent model of FOLFOX-induced neurotoxicity has been developed in rats. Dimiracetam fully reduced hypersensitivity and neurological alterations showing a relevant profile as anti-neuropathic resource.

Keywords FOLFOX - Oxaliplatin · Pain model · Neuropathy $\cdot$ Dimiracetam $\cdot$ Pregabalin $\cdot$ HT-29

\section{Introduction}

The addition of oxaliplatin to 5-fluorouracil (5-FU) and leucovorin (LV) proved to be a significant improvement in the treatment of metastatic colon cancer [1]. This combination, called the FOLFOX regimen, has become part of the world-wide standard of care for the adjuvant and the 
palliative treatment of the disease [2]. Among others, the prominent side effect of FOLFOX therapy is a debilitating, dose-limiting neurotoxicity, which leads to a painful sensory neuropathy. Symptoms evolve in two distinct phases. The acute phase, experienced by $85-95 \%$ of treated patients, is characterized by an increased sensitivity to touching cold items or swallowing cold liquids, throat discomfort, and muscle cramping. It is most pronounced 3 days after a given oxaliplatin infusion [3]. A chronic phase comprises sensory impairment of the distal peripheral nerves of the extremities. Chronic symptoms affect roughly $60,40,20$, and $10 \%$ of treated subjects at 1,6 months, 1 , and 2 years after completion of the FOLFOX regimen, respectively [4-6].

The symptoms of neurotoxicity observed during and after FOLFOX therapy are largely attributable to oxaliplatin [5]. Monotherapy with 5-FU rarely induced neurotoxicity, but fluoropyrimidine metabolites could trigger further nervous alterations [7]. On the other hand, clinical reports are mainly based on the evaluation of the FOLFOX combination effects without distinction among single components and knowledge about possible additive effects. The molecular bases of the neurotoxicity evoked by FOLFOX therapy in its entirety are unknown, even because the lack of a preclinical model of FOLFOX neuropathy. The currently available data about the most neurotoxic component oxaliplatin reveal a complex panel of damages (peripheral nerves, dorsal root ganglia, and central nervous system areas) and altered responses due to maladaptive plasticity (of both neurons and glia; [8-11]) that may be complicated by the presence of 5-FU and LV.

The symptoms arisen after FOLFOX therapy significantly affect patients' daily activities and quality of life, and they are difficult to treat: randomized, controlled clinical trials have to-date demonstrated only for duloxetine a modest treatment effect $[12,13]$. Thus, the discovery of novel effective strategies remains a crucial objective. Recently, dimiracetam, a racetam derivative with nootropic properties, has been proposed as a pain reliever active against chemotherapy-induced neuropathy (CIN) distinguished by an optimal safety profile. It has been shown to be a potent inhibitor of glutamate-induced glutamate release in the rat spinal cord: dimiracetam inhibits NMDA + glycine-stimulated [3H]-D-aspartate release from rat spinal synaptosomes with an IC50 between 10 and $20 \mathrm{nM}$ [14]. Glutamate-induced glutamate release is believed to be directly involved in sensitization of spinal and central pain pathways [15].

The present research undertook the development of an animal model of chemotherapy-induced neuropathic pain evoked by the combined administration of all FOLFOX components. The hypersensitivity to mechanical and thermal noxious and non-noxious stimuli, as well as behavioural, neurological, autonomic parameters, and motor functions were analyzed to offer a clinical relevant tool to study the pathophysiological mechanisms of FOLFOX neurotoxicity and screen new treatments. The properties of dimiracetam were characterized in comparison with currently applied drugs.

\section{Materials and methods}

\section{Animals}

Male Sprague-Dawley (SD) rats (Envigo, Varese, Italy) weighing approximately $200-250 \mathrm{~g}$ at the beginning of the experimental procedure were used. Animals were housed in CeSAL (Centro Stabulazione Animali da Laboratorio, University of Florence) and used at least 1 week after their arrival. Four rats were housed per cage (size $26 \times 41 \mathrm{~cm}$ ) kept at $23 \pm 1{ }^{\circ} \mathrm{C}$ with a $12 \mathrm{~h} \mathrm{light/dark} \mathrm{cycle,} \mathrm{with} \mathrm{lights}$ on at $7 \mathrm{a} . \mathrm{m}$; they were fed a standard laboratory diet and tap water ad libitum. All animal manipulations were carried out according to the Directive 2010/63/EU of the European parliament and of the European Union council (22 September 2010) on the protection of animals used for scientific purposes. The ethical policy of the University of Florence complies with the Guide for the Care and Use of Laboratory Animals of the US National Institutes of Health (NIH Publication no. 85-23, revised 1996; University of Florence assurance number: A5278-01). Formal approval to conduct the experiments described was obtained from the Animal Subjects Review Board of the University of Florence. Experiments involving animals have been reported according to ARRIVE guidelines [16]. All efforts were made to minimize animal suffering and to reduce the number of animals used.

\section{Treatments}

Oxaliplatin $\left(6 \mathrm{mg} \mathrm{kg}^{-1}\right)$ or a mixture of FOLFOX components ( $6 \mathrm{mg} \mathrm{kg}^{-1}$ oxaliplatin, $50 \mathrm{mg} \mathrm{kg}^{-1} 5$-FU, $90 \mathrm{mg} \mathrm{kg}^{-1}$ LV calcium salt) were administered intraperitoneally (i.p.) on days $0,7,14$, and 21 . Oxaliplatin was dissolved in $5 \%$ glucose; the other compounds were dissolved in saline. Regarding to the FOLFOX regimen, 5-FU and LV were administered $2 \mathrm{~h}$ after the oxaliplatin administration. Doses were established accordingly with Robinson et al. [17]. On day 28, FOLFOX-treated animals were divided into two groups, one of them, namely, FOLFOX (5), was treated once again on the same day. The other group received four total administrations-FOLFOX (4).

The effect of the pain relieving drugs was evaluated after acute or repeated treatment. As regards the acute treatment, duloxetine (15 $\mathrm{mg} \mathrm{kg}^{-1}$, per os-p.o.), morphine (10 mg kg-1, subcutaneously-s.c.), pregabalin (20 mg kg${ }^{-1}$, p.o.), and dimiracetam (150 $\mathrm{mg} \mathrm{kg}^{-1}$, p.o.) were administered on day 22 or on day 28 . For the chronic treatment, dimiracetam (150 $\mathrm{mg} \mathrm{kg}^{-1}$, p.o.), pregabalin 
(20 $\mathrm{mg} \mathrm{kg}^{-1}$, p.o.), and duloxetine (15 $\mathrm{mg} \mathrm{kg}^{-1}$, p.o.) were administered daily bis in die (b.i.d.) for three consecutive weeks (starting from day 22). Morphine was dissolved in saline, while dimiracetam, pregabalin, and duloxetine were suspended in $1 \%$ carboxymethylcellulose sodium salt. Body weight was constantly measured during the experiment, and results obtained during treatments are reported in the Supplementary Figure S1.

\section{Paw pressure test}

Paw mechanical sensitivity was determined using a Randall and Selitto apparatus exerting a force that increased at constant rate $\left(32 \mathrm{~g} \mathrm{~s}^{-1}\right)$. The threshold stimulus at which rats withdrew the paw was evaluated before and at different timepoints after treatment. Results represent the group mean of mechanical thresholds expressed as grams. To avoid any possible damage to the rats' paw, the maximum applied force was fixed at $150 \mathrm{~g} \mathrm{[18].}$

\section{Cold plate test}

The rats were placed in a stainless box $(12 \mathrm{~cm} \times 20 \mathrm{~cm} \times 10 \mathrm{~cm})$ with a temperature-controlled cold steel plate as floor. The temperature of the cold plate was kept constant at $4{ }^{\circ} \mathrm{C} \pm 1{ }^{\circ} \mathrm{C}$. Pain-related behaviours (i.e., lifting and licking of the hind paw) were observed and the time (s) of the first sign was recorded. The cutoff time of the latency of paw lifting or licking was set at $60 \mathrm{~s}[10]$.

\section{Von Frey test}

The rats were placed in $20 \times 20 \mathrm{~cm}$ plexiglas boxes equipped with a metallic screen-mesh floor, $20 \mathrm{~cm}$ above the bench. A habituation of 15 min was allowed before the test. An electronic Von Frey hair unit (Ugo Basile, Varese, Italy) was used: the withdrawal threshold was evaluated by applying a force ranging from 0 to $50 \mathrm{~g}$ with a $0.2 \mathrm{~g}$ accuracy. The punctuate stimulus was delivered to the mid-plantar area of each posterior paw from below the meshy floor through a plastic tip and the withdrawal threshold was automatically displayed on the screen. The paw sensitivity threshold was defined as the minimum pressure required to elicit a robust and immediate withdrawal reflex of the paw. Voluntary movements associated with locomotion were not taken as a withdrawal response. Stimuli were applied on each posterior paw with an interval of $5 \mathrm{~s}$. The measure was repeated five times and the final value was obtained by averaging the five measures [10].

\section{Open field test}

Locomotive activity was assessed by the open-field test. The observation apparatus consisted of a $60 \times 60 \mathrm{~cm}$ wooden box with the field bordered by $45 \mathrm{~cm}$ high sidewalls. Time spent in the corners and in the center; number of rearing; number of crossings to the center and the periphery; and spontaneous activity and inactivity of each rat were monitored for $20 \mathrm{~min}$. The data were analyzed using the X-Plo-rat software system version 3.3.

\section{Irwin test}

Each rat was individually placed in a transparent cage $(26 \times 41 \mathrm{~cm})$, and 26 neurobehavioural or physiological parameters were systematically assessed according to Irwin (1968) [19] 4 and 7 weeks after the beginning of the experiment.

Behavioural, autonomic, and neurological manifestations produced by compound administration in rats were evaluated: motor displacement, motor reflexes, stereotypies, grooming, reaction to painful or environmental stimuli (analgesia, irritability), startle response, secretions, excretions, respiratory movements, skin colour and temperature, piloerection, exophthalmos, eyelid and corneal reflexes, muscle tone, ataxia, tremors, head twitches, jumps, convulsions, Straub tail, and other signs or symptoms. For postural reflexes (righting reflex) and other signs such as piloerection, exophthalmia (exaggerated protrusion of the eyeball), ataxia, tremors, and Straub tail, only presence or absence was recorded. Skin colour was evaluated qualitatively (pale, red, or purple); other signs were evaluated semi-quantitatively, according to the observer's personal scale $(0$ to +4 , -4 to 0 , or -4 to +4$)$. The terms sedation and excitation express the final interpretation of a group of signs: reduced motor activity, reduced startle response, eyelid ptosis, and reduced response to manual manipulation, for the former; and increased motor activity, increased startle response, increased response to manual manipulation, and exophthalmia, for the latter. Hyperactivity includes running, jumps, and attempts to escape from the container. Trained observers not informed about the specific treatment of each animal group carried out this test.

\section{Rota-rod test}

Rota-rod apparatus (Ugo Basile, Varese, Italy) consisted of a base platform and a rotating rod with a diameter of $6 \mathrm{~cm}$ and a non-slippery surface. The rod was placed at a height of $25 \mathrm{~cm}$ from the base. The rod, $36 \mathrm{~cm}$ in length, was divided into four equal sections by five disks. Thus, up to four rats were tested simultaneously on the apparatus, with a rod-rotating speed of $10 \mathrm{rpm}$. The integrity of motor coordination was assessed 
based on the number of falls from the rod for a maximum of $600 \mathrm{~s}$. After a maximum of six falls from the rod, the test was suspended and the time was recorded. Each rat was assessed once, and the group mean average score was calculated.

\section{Cell culture and treatments}

The human colon cancer cell line HT-29 was obtained from American Type Culture Collection (Rockville, MD, USA). HT-29 were cultured in DMEM high glucose with $20 \%$ FBS in $5 \% \mathrm{CO}_{2}$ atmosphere at $37^{\circ} \mathrm{C}$. Media contained $2 \mathrm{mM}$ L-glutamine, $1 \%$ essential aminoacid mix, $100 \mathrm{IU} \mathrm{ml}^{-1}$ penicillin, and $100 \mu \mathrm{g} \mathrm{ml}^{-1}$ streptomycin (Sigma, Milan, Italy). HT-29 cells were plated in 96 -wells cell culture $\left(1 \times 10^{4} /\right.$ well $)$ plates, and after $48 \mathrm{~h}$, they were treated with increasing concentrations of FOLFOX components for 24 or $48 \mathrm{~h}$. The molar ratio among oxaliplatin/5-FU/LV used in vivo was maintained (6/50/90 $\mathrm{mg} \mathrm{kg}^{-1}$ are 15/384/176 $\left.\mu \mathrm{g} \mathrm{kg}^{-1}\right)$. Experiments were repeated in the absence and in the presence of dimiracetam $(100 \mu \mathrm{M})$.

\section{Cell viability assay}

HT-29 cell viability was evaluated by the reduction of 3-(4,5-dimethylthiozol-2-yl)-2,5-diphenyltetrazolium bromide (MTT) as an index of mitochondrial compartment functionality. Cells were plated into 96-well cell culture plates, and after $48 \mathrm{~h}$, they were treated as previously described. After extensive washing, $1 \mathrm{mg} \mathrm{ml}^{-1}$ MTT was added into each well and incubated for $30 \mathrm{~min}$ at $37^{\circ} \mathrm{C}$. After washing, the formazan crystals were dissolved in $150 \mu$ dimethyl sulfoxide. The absorbance was measured at $550 \mathrm{~nm}$ [8].

\section{Statistical analysis}

Behavioural measurements were performed on ten rats for each treatment carried out in two different experimental sets. Cell culture measurements were performed in sextuplicate on at least three different cell batches. All experimental results (excepted for the Irwin test) were expressed as means \pm SEM and the analysis of variance was performed by two-way ANOVA. A Bonferroni's significant difference procedure was used as post-hoc comparison. $P$ values $\leq 0.05$ were considered statistically significant.

\section{Results}

\section{Pain threshold measurements: effect of FOLFOX treatment}

On days $0,7,14$, and 21, FOLFOX (4) $\left(6 \mathrm{mg} \mathrm{kg}^{-1}\right.$ oxaliplatin, $50 \mathrm{mg} \mathrm{kg}^{-1} 5$-FU, and $90 \mathrm{mg} \mathrm{kg}^{-1}$ leucovorin calcium salt) or oxaliplatin alone $\left(6 \mathrm{mg} \mathrm{kg}^{-1}\right)$ was administered i.p. once a week for four times; furthermore, a separate group received one more injection of FOLFOX (5) on day 28. Pain measurements were assessed before treatment and $24 \mathrm{~h}$ after, up to day 28 , and once a week up to day 63 . As shown in the Supplementary Figure S1, all treatments reduced the body weight increase in comparison with vehicle-treated animals.

As measured by the paw pressure test, FOLFOX (4) lowered the paw withdrawal threshold in response to a noxious mechanical stimulus starting from day 14 and picking on day $29[43.3 \pm 0.7 \mathrm{~g}$, FOLFOX (4) vs. $66.6 \pm 2.3 \mathrm{~g}$, vehicle]. Oxaliplatin treatment also reduced the paw withdrawal threshold starting from day 14 and picking on day 29 ( $46.7 \pm 1.7 \mathrm{~g}$, oxaliplatin vs. $66.6 \pm 2.3 \mathrm{~g}$, vehicle). The effect of FOLFOX was numerically greater than oxaliplatin alone, but did not reach the threshold of statistical significance. The paw withdrawal threshold induced by a fifth injection of FOLFOX picked in severity on day 42 [41.5 $\pm 1.6 \mathrm{~g}$, FOLFOX (5) vs. $69.4 \pm 1.5 \mathrm{~g}$, control]; this peak was lower than that achieved in the FOLFOX (4) group. By day 64, the paw-withdrawal threshold of the FOLFOX groups had not quite returned to the level of the injection vehicle-treated group, whereas the oxaliplatin group had more completely recovered (Fig. 1a).

The cold plate test measured the response to a thermal non-noxious stimulus as the time latency of licking or retracting paw after a cold stimulus. As shown in Fig. 1b, both FOLFOX and oxaliplatin alone significantly enhanced the sensitivity to cold from day 14 until, day 35 and day 42, respectively, and picking on day $28[15.0 \pm 0.7 \mathrm{~s}$, FOLFOX (4)] and day 35 (12.5 $\pm 0.5 \mathrm{~s}$, oxaliplatin), respectively. A fifth injection of FOLFOX reduced the pain threshold in response to a thermal non-noxious stimulus up to day 42 , reaching a nadir on that day $[10.9 \pm 0.5 \mathrm{~s}$, FOLFOX (5) vs. $23.6 \pm 0.8$ s, control] (Fig. 1b).

Neither FOLFOX nor oxaliplatin alone altered at any timepoint the pain sensitivity in response to a mechanical non-noxious stimulus in the Von Frey apparatus (Fig. 1c).

\section{Pain threshold measurements: effect of single doses of duloxetine, morphine, pregabalin, and dimiracetam against FOLFOX-induced hypersensitivity}

Following single doses of duloxetine $\left(15 \mathrm{mg} \mathrm{kg}^{-1}\right.$, p.o.), morphine (10 $\mathrm{mg} \mathrm{kg}^{-1}$, s.c.), pregabalin $\left(20 \mathrm{mg} \mathrm{kg}^{-1}\right.$, p.o. $)$, or dimiracetam (150 mg kg-1, p.o.) on FOLFOX (4)-treated or oxaliplatin-treated rats on day 22 , or on FOLFOX (5)-treated animals on day 28 , the response to a mechanical noxious stimulus was measured over time up to $45 \mathrm{~min}$ after administration. As depicted in Fig. 2a, duloxetine significantly decreased the hypersensitivity induced by FOLFOX (4) up to 30 min exerting the maximum effect $15 \mathrm{~min}$ after treatment $[57.9 \pm 0.5 \mathrm{~g}$, FOLFOX $(4)+$ duloxetine $]$ and 

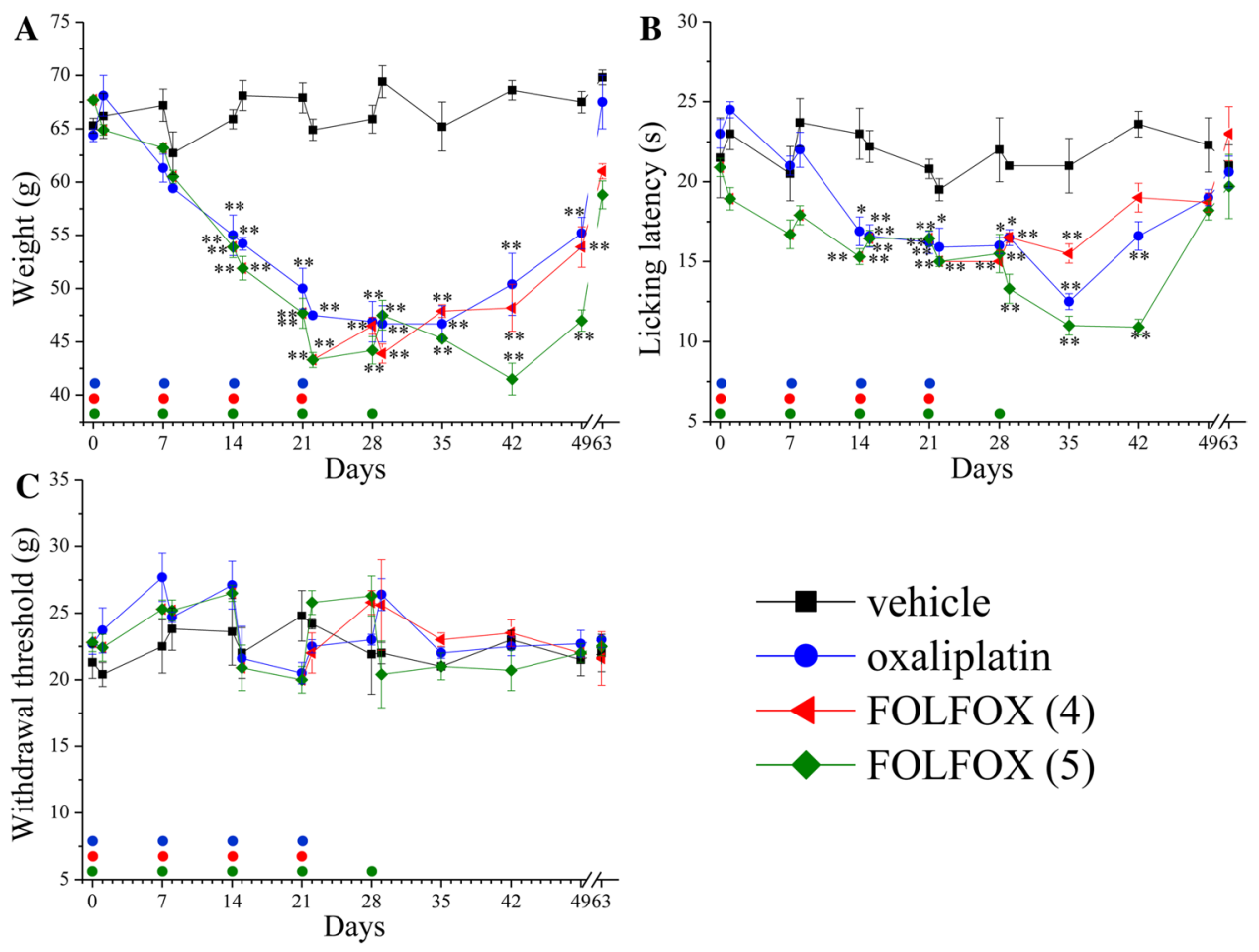

Fig. 1 Pain-related measurements. Oxaliplatin $\left(\begin{array}{lllll}6.0 & \mathrm{mg} & \mathrm{kg}^{-1}\end{array}\right.$ i.p.) (blue circle) or FOLFOX (oxaliplatin $6.0 \mathrm{mg} \mathrm{kg}^{-1}$ i.p/5-FU $50 \mathrm{mg} \mathrm{kg}^{-1}$ i.p./leucovorin $90 \mathrm{mg} \mathrm{kg}^{-1}$ i.p.) [FOLFOX (4) red circle] were injected on days $0,7,14$, and 21 after the behavioural measurements. On day 28, animals were divided into two groups, one was treated once again on the same day with FOLFOX [FOLFOX(5) green circle]. On days $0,1,7,8,14,15,21,22,28,29,35,42,49$, and 63 , the sensibility to a noxious mechanical stimulus was meas-

morphine and pregabalin reduced FOLFOX (4)-induced hypersensitivity 15 min after injection $[56.3 \pm 0.3 \mathrm{~g}$, FOLFOX (4) + morphine; $52.3 \pm 0.3 \mathrm{~g}$, FOLFOX (4) + pregabalin]. Otherwise, dimiracetam had no effect (Fig. 2a). Similar single-dose profiles were also evident in FOLFOX (5)- and in oxaliplatin-treated rats (Fig. 2b, c).

\section{Pain threshold measurements: effect of repeated doses of duloxetine, morphine, pregabalin, and dimiracetam against FOLFOX-induced hypersensitivity}

To evaluate the efficacy of compounds after repeated administrations, FOLFOX (4)-treated animals were daily p.o. treated b.i.d. with pregabalin $\left(20 \mathrm{mg} \mathrm{kg}^{-1}\right)$, duloxetine $\left(15 \mathrm{mg} \mathrm{kg}^{-1}\right)$, or dimiracetam $\left(150 \mathrm{mg} \mathrm{kg}^{-1}\right)$ starting from day 22 for four consecutive weeks. The response to a mechanical noxious stimulus was measured every week over time until $24 \mathrm{~h}$ after administration. As shown in Fig. 3, dimiracetam significantly increased the pain threshold of FOLFOX-injected rats, starting from day 28. Pregabalin was effective from day 35 . The efficacy of both compounds was not different among 1 and $24 \mathrm{~h}$ after treatment suggesting ured by paw pressure test (a), the response to a thermal non-noxious stimulus was evaluated by cold plate test measuring the latency (s) to pain-related behaviours (lifting or licking of the paw) (b), and the withdrawal threshold in response to a non-noxious mechanical stimulus was evaluated by the Von Frey apparatus (c). Control rats were treated with vehicle. Each value represents the mean \pm SEM of ten rats per group, performed in two different experimental sets. $* P<0.05$ and $* * P<0.01$ vs. vehicle + vehicle-treated animals

a stable improved pain threshold. Repeated administrations of duloxetine did not modify the hypersensitivity induced by FOLFOX.

\section{Behavioural, neurological, and motor functions: effect of duloxetine, pregabalin, and dimiracetam on FOLFOX-treated animals}

As evaluated by the open-field test (Table 1), FOLFOX treatment, on day 22 , significantly reduced the number of rearings in comparison with the vehicle group (19.4 \pm 2.9 , FOLFOX vs. $55.2 \pm 6.3$, vehicle). The spontaneous activity was also reduced $(141.2 \pm 20.4$, FOLFOX vs. $387.1 \pm 32.8$, vehicle).

On days 22 and 42, behavioural, autonomic, and neurological parameters were evaluated giving an arbitrary score (from 0 to \pm 4 ), by the Irwin test. On day 22, FOLFOX reduced spontaneous activity, reactivity, and curiosity, whereas the frequencies of tremors, ataxia, piloerections, anemia, and hypothermia were increased (Table 2). Other observational categories were not significantly affected. On day 42 , following 21 days of twice-daily oral treatment with 
Fig. 2 Mechanical noxious stimulus. Effect of duloxetine, morphine, pregabalin, and dimiracetam. Acute treatment. Duloxetine (15 mg kg-1, p.o.), morphine (10 $\mathrm{mg} \mathrm{kg}^{-1}$, s.c.), pregabalin (20 $\mathrm{mg} \mathrm{kg}^{-1}$, p.o.), or dimiracetam $\left(150 \mathrm{mg} \mathrm{kg}^{-1}\right.$, p.o.) was administered on day 22 on FOLFOX (4)- (a) and oxaliplatin-treated (b) animals or on day 28 on FOLFOX (5)-treated (c) animals and the response to a mechanical noxious stimulus was measured $0,15,30$, and 45 min after injection by the paw pressure test. Control rats were treated with vehicles. Each value represents the mean \pm SEM of ten rats per group, performed in two different experimental sets. $* * P<0.01$ vs. vehicle + vehicle treated rats; ${ }^{\wedge} P<0.05$ and ${ }^{\wedge} P<0.01$ vs. time 0 of the same group
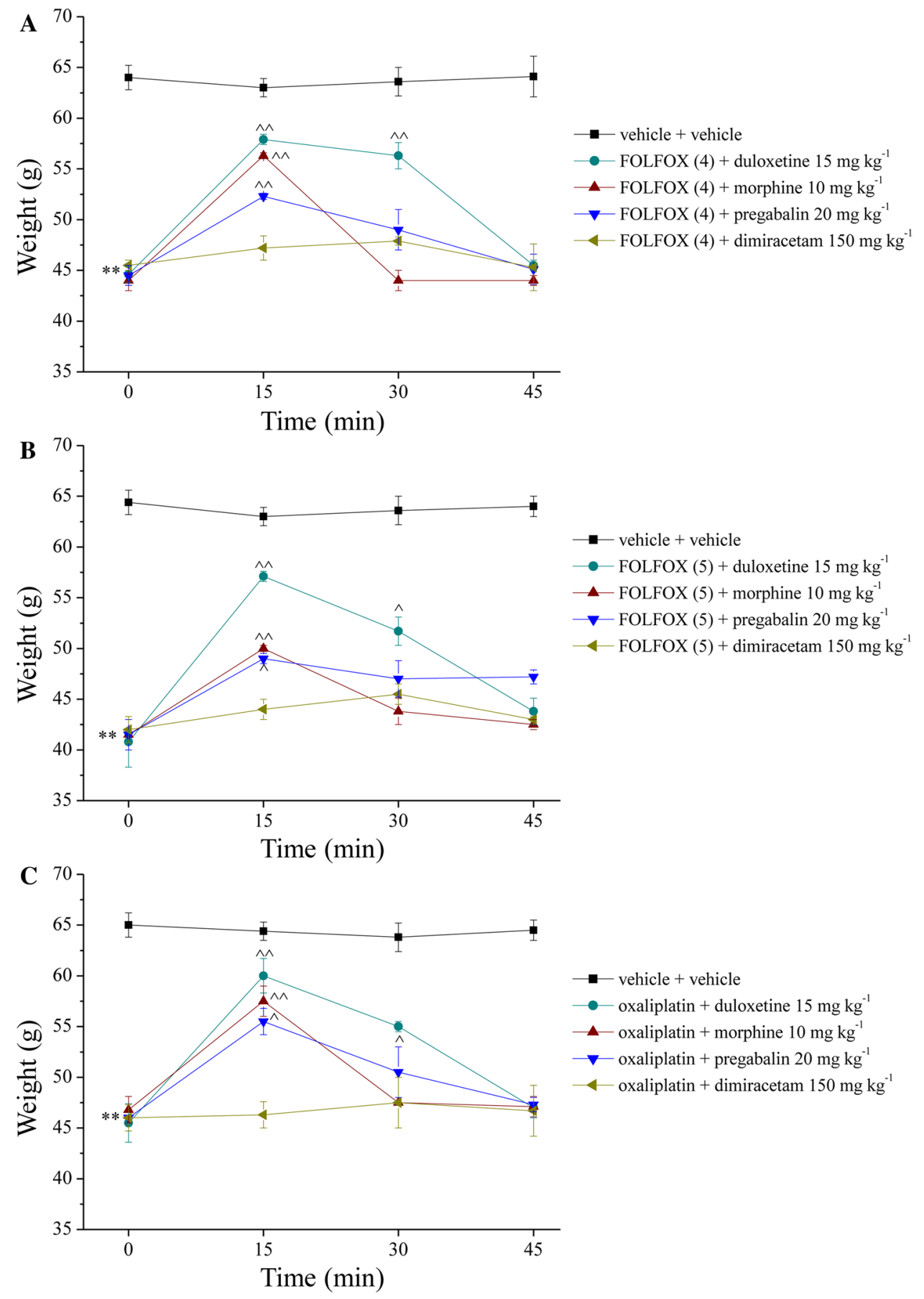

dimiracetam, these FOLFOX effects were nearly completely reversed; pregabalin was similarly effective, whereas duloxetine was less effective (Table 3).

Motor coordination was assessed by the Rota-rod apparatus, before and $24 \mathrm{~h}$ after FOLFOX administration; during the repeated treatments with dimiracetam, pregabalin and duloxetine measurements were performed once a week. Neither FOLFOX nor compounds altered the number of falls in $600 \mathrm{~s}$ in comparison with the control group (Table 4).

\section{Dimiracetam effects on FOLFOX-dependent lethality on colon cancer cells}

To evaluate the potential interaction between dimiracetam treatment and the therapeutic property of FOLFOX, the viability of the human colon cancer cell line HT-29 was measured. Table 5 shows the lack of influence of dimiracetam on the concentration-dependent FOLFOX lethal effect after 24 and $48 \mathrm{~h}$ incubation. 

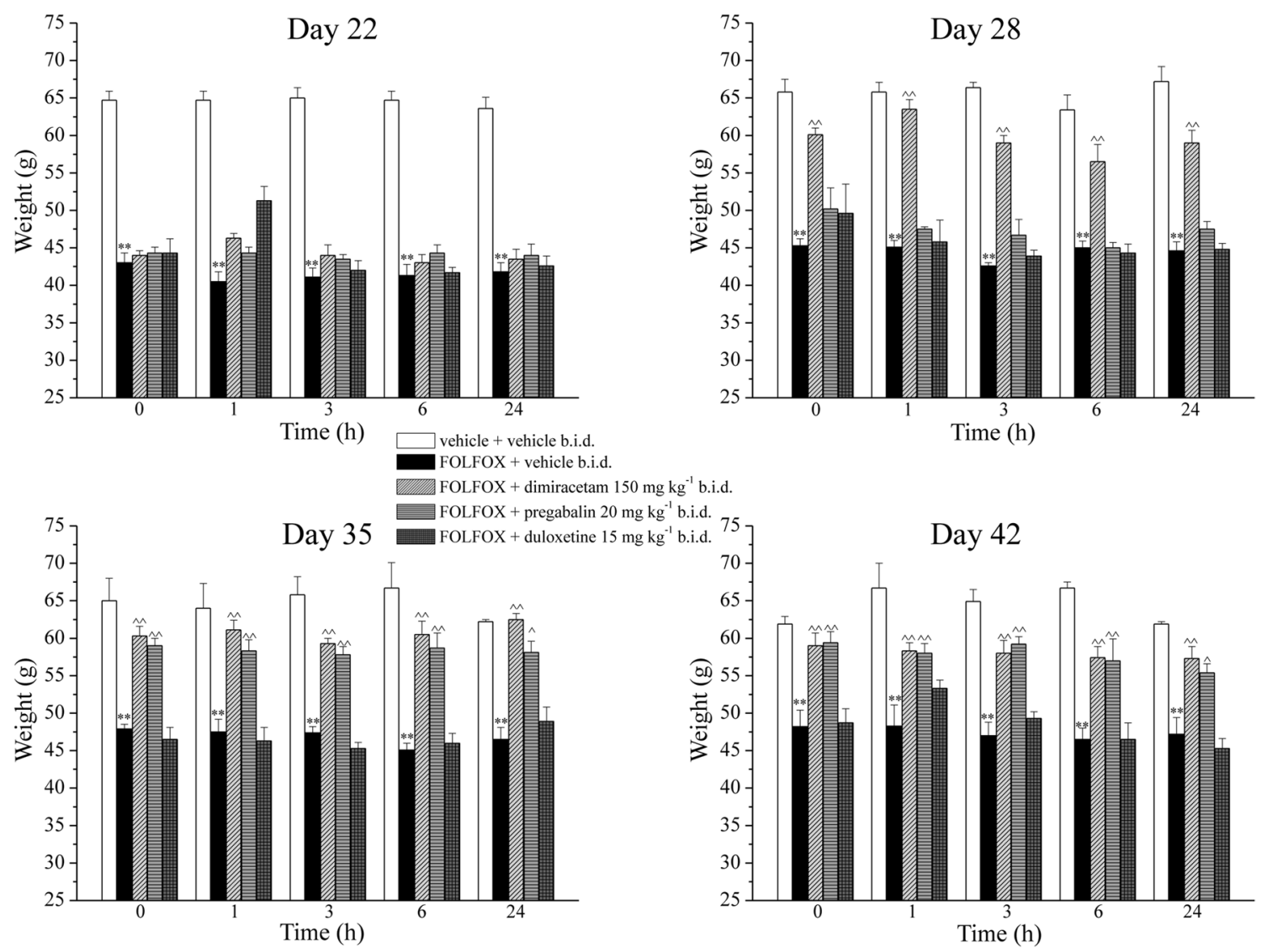

Fig. 3 Mechanical noxious stimulus. Effect of dimiracetam, pregabalin, and duloxetine. Chronic treatment. Starting from day 22, FOLFOX-injected rats (four administrations) were orally administered b.i.d. with dimiracetam $\left(150 \mathrm{mg} \mathrm{kg}^{-1}\right)$, pregabalin $\left(20 \mathrm{mg} \mathrm{kg}^{-1}\right)$, or duloxetine $\left(15 \mathrm{mg} \mathrm{kg}^{-1}\right)$ daily for three consecutive weeks. The response to a mechanical noxious stimulus was assessed by the paw

pressure test $0,1,3,6$, and $24 \mathrm{~h}$ after injection on days $22,28,35$, and 42 . Each value represents the mean \pm SEM of ten rats per group, performed in two different experimental sets. $* * P<0.01$ vs. vehicle + vehicle-treated animals; ${ }^{\wedge} P<0.05$ and ${ }^{\wedge \wedge} P<0.01$ vs. FOLFOX + vehicle-treated animals

\section{Discussion}

A rat model of FOLFOX-induced neuropathy was developed. Animals weekly treated with the complete antineoplastic regimen, oxaliplatin, 5-FU and $\mathrm{LV}$, received in 4 weeks a cumulative oxaliplatin dose of $24 \mathrm{mg} \mathrm{kg}^{-1}$, corresponding to the clinically relevant dose [20] of $888 \mathrm{mg} \mathrm{m}^{-2}$ for the human body, as calculated by the body surface area (BSA) normalization method [21]. The FOLFOX-regimen induced in rats hypersensitivity to mechanical noxious and thermal (cold) non-noxious stimuli, which untreated persists for at least 5 weeks after the last FOLFOX administration. In the present model, we could not detect a change from baseline in the paw-withdrawal threshold in response to a mechanical non-noxious stimulus. Another injection of FOLFOX (the fifth, reaching $30 \mathrm{mg} \mathrm{kg}^{-1}$ of cumulative oxaliplatin, corresponding to $1110 \mathrm{mg} \mathrm{m}^{-2}$ ) enhanced the severity of the hypersensitivity to both mechanical noxious and thermal (cold) non-noxious stimuli, but the course of

recovery in the drug-free follow-up period was similar to the FOLFOX (4).

Behavioural and motor parameters were impaired, since FOLFOX strongly reduced the curiosity and the spontaneous activity of animals even if motor coordination was not altered. A deeper investigation on behavioural, neurologi$\mathrm{cal}$, and autonomic functions highlighted reduced reactivity and curiosity concomitantly with increased frequency of tremors, ataxia, anemia, and hypothermia. These alterations were mighty evident after the last administration of FOLFOX and, although reduced, still present 3 weeks after treatment discontinuation.

Neuropathy is not a common complication of 5-FU therapy [20]. However, some patients have experienced 5-FU-induced neurotoxicity, caused by the accumulation of the fluoropyrimidine metabolites. The alteration of the neurophysiological profile induced by 5-FU may make nerve fibers prone to further degeneration [7]. Otherwise, as evidenced by Andrè and colleagues in the 
Table 1 Open-field test: effect of FOLFOX on behavioural and locomotor activity

\begin{tabular}{lcc}
\hline & \multicolumn{2}{l}{ Treatments } \\
\cline { 2 - 3 } & Vehicle + vehicle & FOLFOX + vehicle \\
\hline Time spent in the corners (s) & $977.8 \pm 22.0$ & $1053.4 \pm 36.3$ \\
Time spent in the center (s) & $21.5 \pm 4.4$ & $11.8 \pm 4.3$ \\
No. of rearings & $55.2 \pm 6.3$ & $19.4 \pm 2.9 * *$ \\
No. of crossings to the center & $6.6 \pm 1.5$ & $2.4 \pm 1.2$ \\
No. of crossings to the & $155.3 \pm 21.4$ & $90.2 \pm 20.8$ \\
periphery & & \\
Spontaneous inactivity (s) & $812.9 \pm 32.8$ & $1099.6 \pm 40.3^{* *}$ \\
Spontaneous activity (s) & $387.1 \pm 32.8$ & $141.2 \pm 20.4 * *$ \\
\hline
\end{tabular}

On day 22, after four administrations of FOLFOX, behavioural and locomotor activity functions were assessed using the open-field test. Time spent in the corners and in the center; number of rearings; number of crossings to the center or to the periphery; spontaneous activity; and spontaneous inactivity of each rat were monitored for $20 \mathrm{~min}$ and analyzed using the X-plo-rat software system. Each value represents the mean \pm S.E.M. of ten rats per group performed in two different experimental sets

$* * P<0.01$ vs. vehicle + vehicle-treated animals

MOSAIC trial, the addition of the platinum-derivative to the combination of 5-FU/LV increased the rate of patients manifesting chronic neuropathy [22]. The present FOLFOX model shows few, if any, differences over the simpler oxaliplatin-only model, except that recovery of in the drug-free follow-up period was more complete, confirming the main neurotoxic role of the platinum derivative. In humans, the association with 5-FU and LV allows a decrease of oxaliplatin cumulative dosage [23], however, introducing new variables in the mechanisms of neuropathy as well as more possibilities of interactions with pain relieving drugs. To note, the pathophysiology of FOLFOX neurotoxicity has not been investigated yet and molecular mechanisms occurring in the chronic form of oxaliplatininduced neuropathy remain unclear. Morphological examination revealed that the primary target of oxaliplatin, and more in general of platinum compounds, is the dorsal root ganglia (DRGs), where the accumulation of the antineoplastic agent triggers nuclear damage [10, 24]. Molecular modifications occurred both in DRGs and in peripheral nerves $[10,25,26]$. To note, despite the low oxaliplatin capability to cross the blood brain barrier [27, 28], dramatic alterations of the CNS were shown. Oxidative damages [29], increased hyper-excitability of the nociceptivespecific neurons in the dorsal horn of the spinal cord [8, 9], were related to oxaliplatin-induced pain. A maladaptive plasticity involves also the glial cells, strongly involved in the development and maintenance of neuropathic pain states [30, 31]. The activation of astrocytes continuously accompanies the treatment with the antineoplastic agent,
Table 2 Irwin test, day 22: effect of FOLFOX on behavioural, autonomic, and neurological parameters

\begin{tabular}{|c|c|c|c|}
\hline & \multicolumn{2}{|l|}{ Treatments } & \multirow[t]{2}{*}{ Limits } \\
\hline & Vehicle + vehicle & FOLFOX + vehicle & \\
\hline \multicolumn{4}{|l|}{ Behaviour } \\
\hline $\begin{array}{l}\text { Spontaneous } \\
\text { activity }\end{array}$ & $4 \pm 0$ & $1.2 \pm 0.2 *$ & $4-0$ \\
\hline Passivity & $0 \pm 0$ & $3.1 \pm 0.3^{*}$ & $0-4$ \\
\hline Cleaning & $4 \pm 0$ & $3.1 \pm 0.3$ & $4-0$ \\
\hline Curiosity & $4 \pm 0$ & $2.2 \pm 0.3^{*}$ & $4-0$ \\
\hline Reactivity & $4 \pm 0$ & $0.9 \pm 0.1 *$ & $4-0$ \\
\hline Vocalization & $0 \pm 0$ & $0 \pm 0$ & $0-4$ \\
\hline \multicolumn{4}{|l|}{ C.N.S. excitement } \\
\hline Straub tail & $0 \pm 0$ & $0 \pm 0$ & $0-4$ \\
\hline Tremors & $0 \pm 0$ & $3.3 \pm 0.4^{*}$ & $0-4$ \\
\hline Convulsions & $0 \pm 0$ & $0 \pm 0$ & $4-0$ \\
\hline \multicolumn{4}{|l|}{ Movement } \\
\hline Ataxia & $0 \pm 0$ & $2.3 \pm 0.1^{*}$ & $0-4$ \\
\hline Stereotipies & $0 \pm 0$ & $1.1 \pm 0.4$ & $0-4$ \\
\hline $\begin{array}{l}\text { Straightening } \\
\text { reflex }\end{array}$ & $4 \pm 0$ & $4 \pm 0$ & $4-0$ \\
\hline \multicolumn{4}{|l|}{ Muscular tone } \\
\hline Physical strength & $4 \pm 0$ & $2.4 \pm 0.8$ & $4-0$ \\
\hline \multicolumn{4}{|l|}{ Reflexes } \\
\hline Palpebral reflex & $4 \pm 0$ & $3 \pm 0.4$ & $4-0$ \\
\hline \multicolumn{4}{|l|}{ Autonomic signs } \\
\hline Piloerection & $0 \pm 0$ & $3.2 \pm 0.2^{*}$ & $0-4$ \\
\hline Exolphthalmos & $0 \pm 0$ & $1.8 \pm 0.5$ & $0-4$ \\
\hline Cyanosis & $0 \pm 0$ & $0 \pm 0$ & $0-4$ \\
\hline Flush & $0 \pm 0$ & $0 \pm 0$ & $0-4$ \\
\hline Pallor & $0 \pm 0$ & $3.8 \pm 0.2^{*}$ & $0-4$ \\
\hline Palpebral opening & $4 \pm 0$ & $4 \pm 0$ & $4-0$ \\
\hline Salivation & $0 \pm 0$ & $0 \pm 0$ & $0-4$ \\
\hline Lacrimation & $0 \pm 0$ & $0 \pm 0$ & $0-4$ \\
\hline $\begin{array}{l}\text { Hypo-hyperther- } \\
\text { mia }\end{array}$ & $0 \pm 0$ & $-2.1 \pm 0.1^{*}$ & $-4 /+4$ \\
\hline Writhing & $0 \pm 0$ & $0 \pm 0$ & $0-4$ \\
\hline \multicolumn{4}{|l|}{ Toxicity } \\
\hline Immediate death & $0 \pm 0$ & $0 \pm 0$ & $0-4$ \\
\hline $\begin{array}{l}\text { Delayed death } \\
\quad(48 \mathrm{~h})\end{array}$ & $0 \pm 0$ & $0 \pm 0$ & $0-4$ \\
\hline
\end{tabular}

On day 22, after four administrations of FOLFOX, the Irwin test was performed in the rat; it involves subjective assessment of behavioural, autonomic, and neurological manifestations in spontaneous, freely moving animals. Skin colour was evaluated qualitatively; other signs were evaluated semi-quantitatively, according to the trained observer's personal scale $(0$ to $+4,-4$ to 0 , or -4 to +4$)$. Each value represents the mean \pm SEM of ten rats per group, performed in two different experimental sets

$* P<0.05$ vs. vehicle + vehicle treated rats 
Table 3 Irwin test, day 42: effect of dimiracetam, pregabalin, duloxetine on FOLFOX-induced behavioural, autonomic and neurological alterations

\begin{tabular}{|c|c|c|c|c|c|c|}
\hline & \multicolumn{5}{|l|}{ Treatments } & \multirow[t]{2}{*}{ Limits } \\
\hline & Vehicle + vehicle & FOLFOX + vehicle & $\begin{array}{l}\text { FOL- } \\
\text { FOX + dimiracetam }\end{array}$ & $\begin{array}{l}\text { FOL- } \\
\text { FOX + prega- } \\
\text { balin }\end{array}$ & $\begin{array}{l}\text { FOL- } \\
\text { FOX + duloxetine }\end{array}$ & \\
\hline \multicolumn{7}{|l|}{ Behaviour } \\
\hline Spontaneous activity & $4 \pm 0$ & $2 \pm 0.1 *$ & $4 \pm 0^{\wedge}$ & $4 \pm 0^{\wedge}$ & $2.8 \pm 0.3$ & $4-0$ \\
\hline Passivity & $0 \pm 0$ & $2.1 \pm 0.2^{*}$ & $0 \pm 0^{\wedge}$ & $0 \pm 0^{\wedge}$ & $1.4 \pm 0.5$ & $0-4$ \\
\hline Cleaning & $4 \pm 0$ & $4 \pm 0$ & $4 \pm 0$ & $4 \pm 0$ & $4 \pm 0$ & $4-0$ \\
\hline Curiosity & $4 \pm 0$ & $2.7 \pm 0.1^{*}$ & $4 \pm 0^{\wedge}$ & $4 \pm 0^{\wedge}$ & $4 \pm 0^{\wedge}$ & $4-0$ \\
\hline Reactivity & $4 \pm 0$ & $2.8 \pm 0.1^{*}$ & $4 \pm 0^{\wedge}$ & $4 \pm 0^{\wedge}$ & $3.1 \pm 0.2$ & $4-0$ \\
\hline Vocalization & $0 \pm 0$ & $0 \pm 0$ & $0 \pm 0$ & $0 \pm 0$ & $0 \pm 0$ & $0-4$ \\
\hline \multicolumn{7}{|l|}{ C.N.S. excitement } \\
\hline Straub tail & $0 \pm 0$ & $0 \pm 0$ & $0 \pm 0$ & $0 \pm 0$ & $0 \pm 0$ & $0-4$ \\
\hline Tremors & $0 \pm 0$ & $0 \pm 0$ & $0 \pm 0$ & $0 \pm 0$ & $0 \pm 0$ & $0-4$ \\
\hline Convulsions & $0 \pm 0$ & $0 \pm 0$ & $0 \pm 0$ & $0 \pm 0$ & $0 \pm 0$ & $4-0$ \\
\hline \multicolumn{7}{|l|}{ Movement } \\
\hline Ataxia & $0 \pm 0$ & $0 \pm 0$ & $0 \pm 0$ & $0 \pm 0$ & $0 \pm 0$ & $0-4$ \\
\hline Stereotipies & $0 \pm 0$ & $0 \pm 0$ & $0 \pm 0$ & $0 \pm 0$ & $0 \pm 0$ & $0-4$ \\
\hline Straightening reflex & $4 \pm 0$ & $4 \pm 0$ & $4 \pm 0$ & $4 \pm 0$ & $4 \pm 0$ & $4-0$ \\
\hline \multicolumn{7}{|l|}{ Muscular tone } \\
\hline Physical strength & $4 \pm 0$ & $4 \pm 0$ & $4 \pm 0$ & $4 \pm 0$ & $4 \pm 0$ & $4-0$ \\
\hline \multicolumn{7}{|l|}{ Reflexes } \\
\hline Palpebral reflex & $4 \pm 0$ & $4 \pm 0$ & $4 \pm 0$ & $4 \pm 0$ & $4 \pm 0$ & $4-0$ \\
\hline \multicolumn{7}{|l|}{ Autonomic signs } \\
\hline Piloerection & $0 \pm 0$ & $2.1 \pm 0.2^{*}$ & $1.1 \pm 0.1^{\wedge}$ & $1 \pm 0.2^{\wedge}$ & $1.3 \pm 0.1^{\wedge}$ & $0-4$ \\
\hline Exolphthalmos & $0 \pm 0$ & $0 \pm 0$ & $0 \pm 0$ & $0 \pm 0$ & $0 \pm 0$ & $0-4$ \\
\hline Cyanosis & $0 \pm 0$ & $0 \pm 0$ & $0 \pm 0$ & $0 \pm 0$ & $0 \pm 0$ & $0-4$ \\
\hline Flush & $0 \pm 0$ & $0 \pm 0$ & $0 \pm 0$ & $0 \pm 0$ & $0 \pm 0$ & $0-4$ \\
\hline Pallor & $0 \pm 0$ & $3 \pm 0.2 *$ & $1.2 \pm 0.1^{\wedge}$ & $1.2 \pm 0.1^{\wedge}$ & $3 \pm 0.3$ & $0-4$ \\
\hline Palpebral opening & $4 \pm 0$ & $4 \pm 0$ & $4 \pm 0$ & $4 \pm 0$ & $4 \pm 0$ & $4-0$ \\
\hline Salivation & $0 \pm 0$ & $0 \pm 0$ & $0 \pm 0$ & $0 \pm 0$ & $0 \pm 0$ & $0-4$ \\
\hline Lacrimation & $0 \pm 0$ & $0 \pm 0$ & $0 \pm 0$ & $0 \pm 0$ & $0 \pm 0$ & $0-4$ \\
\hline Hypo-hyperthermia & $0 \pm 0$ & $0 \pm 0$ & $0 \pm 0$ & $0 \pm 0$ & $0 \pm 0$ & $-4 /+4$ \\
\hline Writhing & $0 \pm 0$ & $0 \pm 0$ & $0 \pm 0$ & $0 \pm 0$ & $0 \pm 0$ & $0-4$ \\
\hline \multicolumn{7}{|l|}{ Toxicity } \\
\hline Immediate death & $0 \pm 0$ & $0 \pm 0$ & $0 \pm 0$ & $0 \pm 0$ & $0 \pm 0$ & $0-4$ \\
\hline Delayed death (48 h) & $0 \pm 0$ & $0 \pm 0$ & $0 \pm 0$ & $0 \pm 0$ & $0 \pm 0$ & $0-4$ \\
\hline
\end{tabular}

On day 42, following 21 days of twice daily oral administration of dimiracetam $\left(150 \mathrm{mg} \mathrm{kg}^{-1}\right)$, pregabalin $\left(20 \mathrm{mg} \mathrm{kg}^{-1}\right)$, or duloxetine $\left(15 \mathrm{mg} \mathrm{kg}^{-1}\right.$ ), the Irwin test was performed on FOLFOX-injected rats (four administrations). Skin colour was evaluated qualitatively; other signs were evaluated semi-quantitatively, according to the observer's personal scale ( 0 to $+4,-4$ to 0 , or -4 to +4$)$. Each value represents the mean \pm S.E.M. of ten rats per group, performed in two different experimental sets

$* P<0.05$ vs. vehicle + vehicle; ${ }^{\wedge} P<0.05$ vs. FOLFOX + vehicle

suggesting a complex involvement of astrocytes in pain chronicization [10, 11, 32].

Although the evidences collected up to now about the neurotoxicity evoked by the platinum derivative, effective treatments against FOLFOX-induced neuropathy are lacking. Duloxetine is the only recommended intervention. Nevertheless, it is not completely effective and did not work for everyone [33]. Tricyclic antidepressants are not recommended but clinicians may use them after discussion with patients about the limited effectiveness. The antiepileptic drugs, pregabalin and gabapentin, have not well-established efficacy as resulted from clinical trials, but given the limited options for managing neuropathy, their clinical use is encouraged [13]. 
Table 4 Rota-rod test: evaluation of motor coordination

\begin{tabular}{|c|c|c|c|c|c|}
\hline \multirow[t]{2}{*}{ Day } & \multicolumn{5}{|l|}{ Treatments } \\
\hline & Vehicle + vehicle & FOLFOX + vehicle & $\begin{array}{l}\text { FOL- } \\
\text { FOX + dimiracetam }\end{array}$ & $\begin{array}{l}\text { FOL- } \\
\text { FOX + prega- } \\
\text { balin }\end{array}$ & $\begin{array}{l}\text { FOL- } \\
\text { FOX+dulox- } \\
\text { etine }\end{array}$ \\
\hline 0 & $4.0 \pm 1.0$ & $4.4 \pm 0.4$ & & & \\
\hline 1 & $1.3 \pm 0.3$ & $0.7 \pm 0.2$ & & & \\
\hline 7 & $1.0 \pm 0.6$ & $0.7 \pm 0.2$ & & & \\
\hline 8 & $0.0 \pm 0.0$ & $0.0 \pm 0.0$ & & & \\
\hline 14 & $2.0 \pm 1.5$ & $1.9 \pm 0.5$ & & & \\
\hline 15 & $0.0 \pm 0.0$ & $0.5 \pm 0.3$ & & & \\
\hline 21 & $2.0 \pm 1.5$ & $1.9 \pm 0.6$ & & & \\
\hline 22 & $1.2 \pm 0.5$ & $1.5 \pm 0.5$ & $1.2 \pm 0.3$ & $1.0 \pm 0.9$ & $1.5 \pm 0.6$ \\
\hline 28 & $0.8 \pm 0.3$ & $1.0 \pm 0.3$ & $0.8 \pm 0.5$ & $1.0 \pm 0.7$ & $1.2 \pm 0.8$ \\
\hline 35 & $1.0 \pm 0.6$ & $0.5 \pm 0.3$ & $1.4 \pm 1.2$ & $1.3 \pm 0.4$ & $1.4 \pm 1.2$ \\
\hline 42 & $0.7 \pm 0.7$ & $0.8 \pm 0.3$ & $0.0 \pm 0.0$ & $0.5 \pm 0.4$ & $0.2 \pm 0.2$ \\
\hline 49 & $0.0 \pm 0.0$ & $1.2 \pm 1.3$ & $0.6 \pm 0.4$ & $0.0 \pm 0.0$ & $0.0 \pm 0.0$ \\
\hline 63 & $0.0 \pm 0.0$ & $0.3 \pm 0.3$ & $0.0 \pm 0.0$ & $0.0 \pm 0.0$ & $0.0 \pm 0.0$ \\
\hline
\end{tabular}

From day 0, every week, the integrity of the animals' motor coordination was assessed using a Rota-rod apparatus measuring the number of falls from the rotating rod in a fixed time $(600 \mathrm{~s})$. Measurements were performed before and $24 \mathrm{~h}$ after FOLFOX administration (four administrations) during the first 4 weeks, and once a week, during treatments with dimiracetam, pregabalin and duloxetine. Each value represents the mean \pm SEM of ten rats per group, performed in two different experimental sets

Table 5 HT-29 cell viability after 24 and $48 \mathrm{~h}$ incubation

\begin{tabular}{|c|c|c|c|c|c|}
\hline \multirow[t]{3}{*}{ FOLFOX concentration $(\mu \mathrm{M})$} & & \multicolumn{4}{|l|}{ Cell viability $\%$} \\
\hline & & \multicolumn{2}{|l|}{$24 \mathrm{~h}$ incubation } & \multicolumn{2}{|l|}{$48 \mathrm{~h}$ incubation } \\
\hline & & Control & Dimiracetam $(100 \mu \mathrm{M})$ & Control & Dimiracetam $(100 \mu \mathrm{M})$ \\
\hline Oxaliplatin & 0 & $100 \pm 3.95$ & $100 \pm 3.63$ & $100 \pm 3.95$ & $100 \pm 3.63$ \\
\hline 5-Fluorouracil & 0 & & & & \\
\hline Leucovorin & 0 & & & & \\
\hline Oxaliplatin & 0.3 & $97.50 \pm 3.80$ & $105.33 \pm 3.98$ & $104.96 \pm 4.74$ & $96.32 \pm 5.21$ \\
\hline 5-Fluorouracil & 7.7 & & & & \\
\hline Leucovorin & 3.5 & & & & \\
\hline Oxaliplatin & 1 & $91.22 \pm 2.46$ & $106.20 \pm 3.22$ & $108.49 \pm 3.54$ & $95.83 \pm 4.80$ \\
\hline 5-Fluorouracil & 25.6 & & & & \\
\hline Leucovorin & 11.6 & & & & \\
\hline Oxaliplatin & 3 & $107.17 \pm 4.45$ & $100.13 \pm 5.24$ & $102.99 \pm 6.36$ & $92.40 \pm 3.05$ \\
\hline 5-Fluorouracil & 76.8 & & & & \\
\hline Leucovorin & 35 & & & & \\
\hline Oxaliplatin & 10 & $91.76 \pm 2.89$ & $63.27 \pm 3.02 * * *$ & $96.68 \pm 4.20$ & $61.55 \pm 2.06^{* * *}$ \\
\hline 5-Fluorouracil & 256 & & & & \\
\hline Leucovorin leucovorin $136 \mu \mathrm{M}$ & 116 & & & & \\
\hline Oxaliplatin & 30 & $66.52 \pm 2.60 * * *$ & $36.92 \pm 1.54 * * *$ & $72.90 \pm 2.57 * * *$ & $35.14 \pm 0.41 * * *$ \\
\hline 5-Fluorouracil & 768 & & & & \\
\hline Leucovorin leucovorin $410 \mu \mathrm{M}$ & 348 & & & & \\
\hline
\end{tabular}

HT-29 cells were treated with increasing concentrations of FOLFOX components in the presence or in the absence of $100 \mu \mathrm{M}$ dimiracetam. Incubation was allowed for $24 \mathrm{~h}$ or $48 \mathrm{~h}$. Cell viability was measured by MTT assay. Control condition was arbitrarily set as $100 \%$ and values are expressed as the mean \pm SEM of three experiments

$* * * P<0.001$ in comparison with control (FOLFOX $0 \mu \mathrm{M}$ ) 
Noteworthy, current pharmacotherapy of FOLFOXdependent neuropathy was developed by modelling pain using oxaliplatin alone (in vitro or in vivo) without considering the complications introduced in humans by the presence of 5-FU and LV. In the present preclinical model of FOLFOX-induced neuropathy, duloxetine, and at a lesser extent morphine or pregabalin, was active after an acute administration. Duloxetine exerted the longest action in comparison with the other two compounds, while morphine is the less effective, confirming the low effectiveness of opioids in CINs [34]. Interestingly, in the present experiments emerged that the effect of duloxetine is symptomatic only since a repeated twice daily treatment does not evoke a prolonged, all day long, pain relieving action. Pregabalin took a "preventive" effect (evaluated as a relief maintained over $24 \mathrm{~h}$ ) after 14 days of treatment. Morphine was not repeatedly administered, since the wellknown development of tolerance to the anti-nociceptive effect $[35,36]$.

The racetam derivative dimiracetam was not effective after a single administration. On the contrary a repeated treatment fully reduced the FOLFOX-induced hypersensitivity starting after 7 days of treatment. The effect was long lasting (at least $24 \mathrm{~h}$ ) without the development of tolerance. Moreover, dimiracetam reduced the behavioural, neurological, and autonomic alterations evoked by the antineoplastic agents. Racetam, even called nootropics, are a family of 2-pyrrolidinone derivatives designed in the sixties and profiled as cognition enhancers. Racetam compounds, such as nefiracetam and levetiracetam, have shown antihyperalgesic effect in animal models of neuropathic pain $[37,38]$. Dimiracetam itself has been already reported to be active against neuropathy induced by the chronic constriction injury of the sciatic nerve and diabetic neuropathy [39]. Moreover, dimiracetam was effective in preclinical models of chemotherapy-induced neuropathic pain triggered by the anticancer compounds oxaliplatin or sorafenib or by antiretroviral drugs $[14,40]$. To note, the racetam derivative as well as pregabalin act throughout the glutamatergic system, since pregabalin reduces the release of synaptic vesicles from glutamatergic neurons [41], and dimiracetam decreases the NMDA-induced release of glutamate in synaptosomal preparations from rat spinal cord [14]. Recently, we reported that the glutamate release was enhanced in cerebrocortical nerve terminals of oxaliplatin-treated rats [42]. Furthermore, astrocytes, major players in the oxaliplatin-induced chronic neuropathy, once activated, amplify glutamate signals acting on presynaptic AMPA receptors [43]. These evidences suggest that the central nervous system is a primary target of the racetam compound. It is relevant to note the absence of interaction between dimiracetam and the lethal effect exerted by FOLFOX on the human colon cancer cells HT-29, suggesting a safety profile when used in combination with anticancer agents. Dimiracetam is currently in clinical development for treatment and/or prevention of CIN.

\section{Conclusion}

Our results describe for the first time a protocol of FOLFOX administration able to induce in the rat the onset of a chronic neuropathy characterized by hypersensitivity to mechanical and thermal (cold) stimuli as well as impairment of behavioural, neurological, and autonomic parameters. Dimiracetam, repeatedly administered, completely counteracts FOLFOX-induced neuropathic alterations. The optimal safety profile of this compound suggests its possible use as treatment of the FOLFOX-induced neuropathy.

Acknowledgements This research was funded by the Italian Ministry of Instruction, University and Research (MIUR), University of Florence and Metys Pharmaceuticals.

Author contributions MM and LM performed the experimental tests; LDCM, MM, and CF performed the statistical analysis of data; LDCM, CG, CF, and MS participated in the design of the study; LDCM, MM, CG, CF, and MS conceived of the study, and participated in its coordination and helped to draft the manuscript. All authors read and approved the final manuscript.

\section{Compliance with ethical standards}

Conflict of interest $\mathrm{CG}, \mathrm{MS}$, and $\mathrm{CF}$ have a patent (patent $\mathrm{n}$. EP2857017) issued. MS and CF report personal fees, outside the submitted work, from Metys Pharma as CEO and as employee, respectively. LDCM, MM, and LM declare that have no conflict of interest.

Ethical approval All applicable international, national, and/or institutional guidelines for the care and use of animals were followed. Procedures were approved by the Italian Ministry of Health, decree No. 54/2014B.

\section{References}

1. Rothenberg ML, Oza AM, Bigelow RH, Berlin JD, Marshall JL, Ramanathan RK, Hart LL, Gupta S, Garay CA, Burger BG, Le Bail N, Haller DG (2003) Superiority of oxaliplatin and fluorouracil-leucovorin compared with either therapy alone in patients with progressive colorectal cancer after irinotecan and fluorouracil-leucovorin: interim results of a phase III trial. J Clin Oncol 21:2059-2069

2. Lonardi S, Sobrero A, Rosati G, Di Bartolomeo M, Ronzoni M, Aprile G, Scartozzi M, Banzi M, Zampino MG, Pasini F, Marchetti P, Cantore M, Zaniboni A, Rimassa L, Ciuffreda L, Ferrari D, Barni S, Zagonel V, Maiello E, Rulli E, Labianca R, TOSCA (Three or Six Colon Adjuvant) Investigators (2016) Phase III trial comparing 3-6 months of adjuvant FOLFOX4/XELOX in stage II-III colon cancer: safety and compliance in the TOSCA trial, 2016. Ann Oncol 27(11):2074-2081

3. Pachman DR, Qin R, Seisler DK, Smith EM, Beutler AS, Ta LE, Lafky JM, Wagner-Johnston ND, Ruddy KJ, Dakhil S, Staff NP, Grothey A, Loprinzi CL (2015) Clinical course of 
oxaliplatin-induced neuropathy: results from the randomized phase III trial N08CB (Alliance). J Clin Oncol 33(30):3416-3422

4. Stefansson M, Nygren P (2016) Oxaliplatin added to fluoropyrimidine for adjuvant treatment of colorectal cancer is associated with long-term impairment of peripheral nerve sensory function and quality of life. Acta Oncol 55(9-10):1227-1235 (Epub 2016 Aug 23)

5. André T, Boni C, Navarro M, Tabernero J, Hickish T, Topham C, Bonetti A, Clingan P, Bridgewater J, Rivera F, de Gramont A (2009) Improved overall survival with oxaliplatin, fluorouracil, and leucovorin as adjuvant treatment in stage II or III colon cancer in the MOSAIC trial. J Clin Oncol 27(19):3109-3116

6. Land SR, Kopec JA, Cecchini RS, Ganz PA, Wieand HS, Colangelo LH, Murphy K, Kuebler JP, Seay TE, Needles BM, Bearden JD, Colman LK, Lanier KS, Pajon ER Jr, Cella D, Smith RE, O'Connell MJ, Costantino JP, Wolmark N (2007) Neurotoxicity from oxaliplatin combined with weekly bolus fluorouracil and leucovorin as surgical adjuvant chemotherapy for stage II and III colon cancer: NSABP C-07. J Clin Oncol 25(16):2205-2211

7. Werbrouck BF, Pauwels WJ, De Bleecker JL (2008) A case of 5-fluorouracil-induced peripheral neuropathy. Clin Toxicol (Phila) 46(3):264-266

8. Di Cesare Mannelli L, Pacini A, Corti F, Boccella S, Luongo L, Esposito E, Cuzzocrea S, Maione S, Calignano A, Ghelardini C (2015) Antineuropathic profile of $N$-palmitoylethanolamine in a rat model of oxaliplatin-induced neurotoxicity. PLoS One 10(6):e0128080. doi:10.1371/journal.pone.0128080 (eCollection 2015)

9. Renn CL, Carozzi VA, Rhee P, Gallop D, Dorsey SG, Cavaletti G (2011) Multimodal assessment of painful peripheral neuropathy induced by chronic oxaliplatin-based chemotherapy in mice. Mol Pain 7:29

10. Di Cesare Mannelli L, Pacini A, Bonaccini L, Zanardelli M, Mello T, Ghelardini C (2013) Morphologic features and glial activation in rat oxaliplatin-dependent neuropathic pain. J Pain 14(12):1585-1600

11. Di Cesare Mannelli L, Pacini A, Micheli L, Tani A, Zanardelli M, Ghelardini C (2014) Glial role in oxaliplatin-induced neuropathic pain. Exp Neurol 261:22-33

12. Lavoie Smith EM, Pang H, Cirrincione C, Fleishman S, Paskett ED, Ahles T, Bressler LR, Fadul CE, Knox C, Le-Lindqwister N, Gilman PB, Shapiro CL, For the Alliance for Clinical Trials in Oncology (2013) Effect of duloxetine on pain, function, and quality of life among patients with chemotherapy-induced painful peripheral neuropathy: a randomized clinical trial. JAMA 309(13):1359-1367

13. Hershman DL, Lacchetti C, Dworkin RH, Lavoie Smith EM, Bleeker J, Cavaletti G, Chauhan C, Gavin P, Lavino A, Lustberg MB, Paice J, Schneider B, Smith ML, Smith T, Terstriep S, Wagner-Johnston N, Bak K, Loprinzi CL, American Society of Clinical Oncology (2014) Prevention and management of chemotherapy-induced peripheral neuropathy in survivors of adult cancers: American Society of Clinical Oncology clinical practice guideline. J Clin Oncol 32:1941-1967

14. Fariello RG, Ghelardini C, Di Cesare Mannelli L, Bonanno G, Pittaluga A, Milanese M, Misiano P, Farina C (2014) Broad spectrum and prolonged efficacy of dimiracetam in models of neuropathic pain. Neuropharmacology 81:223-254

15. Latremoliere A, Woolf CJ (2009) Central sensitization: a generator of pain hypersensitivity by central neural plasticity. J Pain 10(9):895-926

16. McGrath JC, Lilley E (2015) Implementing guidelines on reporting research using animals (ARRIVE etc.): new requirements for publication in BJP. Br J Pharmacol 172(13):3189-3193

17. Robinson SM, Mann J, Vasilaki A, Mathers J, Burt AD, Oakley F, White SA, Mann DA (2013) Pathogenesis of FOLFOX induced sinusoidal obstruction syndrome in a murine chemotherapy model. J Hepatol 59(2):318-326

18. Leighton GE, Rodriguez RE, Hill RG, Hughes J (1988) K-Opioid agonists produce antinociception after i.v. and i.c.v. but not intrathecal administration in the rat. Br J Pharmacol 93:553-560

19. Irwin S (1968) Comprehensive observational assessment: Ia. A systematic, quantitative procedure for assessing the behavioral and physiologic state of the mouse. Psychopharmacologia 13(3):222-257

20. Argyriou AA, Velasco R, Briani C, Cavaletti G, Bruna J, Alberti P, Cacciavillani M, Lonardi S, Santos C, Cortinovis D, Cazzaniga M, Kalofonos HP (2012) Peripheral neurotoxicity of oxaliplatin in combination with 5-fluorouracil (FOLFOX) or capecitabine (XELOX): a prospective evaluation of 150 colorectal cancer patients. Ann Oncol 23:3116-3122

21. Reagan-Shaw S, Nihal M, Ahmad N (2008) Dose translation from animal to human studies revisited. FASEB J 22(3):659-661

22. Andrè T, Boni C, Mounedji-Boudiaf L, Navarro M, Tabernero J, Hickish T, Topham C, Zaninelli M, Clingan P, Bridgewater J, Tabah-Fisch I, de Gramont A, For the Multicenter International Study of Oxaliplatin/5-Fluorouracil/Leucovorin in the Adjuvant Treatment of Colon Cancer (MOSAIC) Investigators et al (2004) Oxaliplatin, fluorouracil, and leucovorin as adjuvant treatment for colon cancer. N Engl J Med 350:2343-2351

23. André T, Louvet C, Maindrault-Goebel F, Gramont AD (2001) Oxaliplatin in combination with 5-fluoro-uracil and folinic acid as treatment of metastatic colorectal cancer. Bull Cancer 88:S20-5

24. Cavaletti G, Tredici G, Petruccioli MG, Dondè E, Tredici P, Marmiroli P, Minoia C, Ronchi A, Bayssas M, Etienne GG (2001) Effects of different schedules of oxaliplatin treatment on the peripheral nervous system of the rat. Eur J Cancer 37(18):2457-2463

25. Nixon RA, Lewis SE, Marotta CA (1987) Posttranslational modification of neurofilament proteins by phosphate during axoplasmic transport in retinal ganglion cell neurons. J Neurosci 7:1145-1158

26. Carlton SM, Du J, Tan HY, Nesic O, Hargett GL, Bopp AC, Yamani A, Lin Q, Willis WD, Hulsebosch CE (2009) Peripheral and central sensitization in remote spinal cord regions contribute to central neuropathic pain after spinal cord injury. Pain 147:265-276

27. Jacobs SS, Fox E, Dennie C, Morgan LB, McCully CL, Balis FM (2005) Plasma and cerebrospinal fluid pharmacokinetics of intravenous oxaliplatin, cisplatin, and carboplatin in nonhuman an primates. Clin Cancer Res 11:1669-1674

28. Huang ZZ, Li D, Ou-Yang HD, Liu CC, Liu XG, Ma C, Wei JY, Liu Y, Xin WJ (2016) Cerebrospinal fluid oxaliplatin contributes to the acute pain induced by systemic administration of oxaliplatin. Anesthesiology 124(5):1109-1121

29. Di Cesare Mannelli L, Zanardelli M, Failli P, Ghelardini C (2012) Oxaliplatin-induced neuropathy: oxidative stress as pathological mechanism. Protective effect of silibinin. J Pain 13(3):276-284

30. Marchand F, Perretti M, McMahon SB (2005) Role of the immune system in chronic pain. Nat Rev Neurosci 6:521-532

31. Wieseler-Frank J, Maier SF, Watkins LR (2004) Glial activation and pathological pain. Neurochem Int 45:389-395

32. Pacini A, Micheli L, Maresca M, Branca JJ, McIntosh JM, Ghelardini C, Di Cesare Mannelli L (2016) The $\alpha 9 \alpha 10$ nicotinic receptor antagonist $\alpha$-conotoxin RgIA prevents neuropathic pain induced by oxaliplatin treatment. Exp Neurol 282:37-48

33. Smith EM, Pang H, Ye C, Cirrincione C, Fleishman S, Paskett ED, Ahles T, Bressler LR, Le-Lindqwister N, Fadul CE, Loprinzi C, Shapiro CL (2015) Alliance for clinical trials in oncology. Predictors of duloxetine response in patients with oxaliplatin-induced painful chemotherapy-induced peripheral neuropathy (CIPN): a secondary analysis of randomised controlled trial-CALGB/ 
alliance 170601. Eur J Cancer Care (Engl). doi:10.1111/ecc.12421 (Epub ahead of print)

34. Ling B, Coudoré F, Decalonne L, Eschalier A, Authier N (2008) Comparative antiallodynic activity of morphine, pregabalin and lidocaine in a rat model of neuropathic pain produced by one oxaliplatin injection. Neuropharmacology 55:724-728

35. Fernandes M, Kluwe S, Coper H (1977) The development of tolerance to morphine in the rat. Psychopharmacology (Berl) 54(2):197-201

36. Williams JT, Ingram SL, Henderson G, Chavkin C, von Zastrow M, Schulz S, Koch T, Evans CJ, Christie MJ (2013) Regulation of mu-opioid receptors: desensitization, phosphorylation, internalization, and tolerance. Pharmacol Rev 65(1):223-254

37. Rashid MH, Ueda H (2002) Nonopioid and neuropathy-specific analgesic action of the nootropic drug nefiracetam in mice. J Pharmacol Exp Ther 303:226-231

38. Ozcan M, Ayar A, Canpolat S, Kutlu S (2008) Antinociceptive efficacy of levetiracetam in a mice model for painful diabetic neuropathy. Acta Anaesthesiol Scand 52:926-930
39. Farina C, Gagliardi S, Ghelardini C, Martinelli M, Norcini M, Parini C, Petrillo P, Ronzoni S (2008) Synthesis and biological evaluation of novel dimiracetam derivatives useful for the treatment of neuropathic pain. Bioorg Med Chem 16(6):3224-3232

40. Di Cesare Mannelli L, Maresca M, Farina C, Scherz MW, Ghelardini C (2015) A model of neuropathic pain induced by sorafenib in the rat: effect of dimiracetam. Neurotoxicology 50:101-107

41. Micheva KD, Taylor CP, Smith SJ (2006) Pregabalin reduces the release of synaptic vesicles from cultured hippocampal neurons. Mol Pharmacol 70:467-476

42. Di Cesare Mannelli L, Marcoli M, Micheli L, Zanardelli M, Maura G, Ghelardini C, Cervetto C (2015) Oxaliplatin evokes $\mathrm{P} 2 \times 7$-dependent glutamate release in the cerebral cortex: a pain mechanism mediated by Pannexin 1. Neuropharmacology. 97:133-141

43. Werry EL, Liu GJ, Bennett MR (2006) Glutamate-stimulated ATP release from spinal cord astrocytes is potentiated by substance $P$. J Neurochem 99:924-936 